\title{
An Evaluation of Epidemic Intelligence Service Alumni in Public Health Leadership Roles
}

\section{Marvin So ( $\nabla$ mrmarvinso@gmail.com )}

Oak Ridge Institute for Science and Education https://orcid.org/0000-0002-3639-0472

\section{Andrea Winquist}

Centers for Disease Control and Prevention

\section{Shelby Fisher}

Williams College

\section{Danice Eaton}

US Public Health Service Commissioned Corps

Dianna Carroll

US Public Health Service Commissioned Corps

\section{Patricia Simone}

Centers for Disease Control and Prevention

\section{Eric Pevzner}

US Public Health Service Commissioned Corps

\section{Wences Arvelo}

Centers for Disease Control and Prevention

\section{Research Article}

Keywords: Workforce, leadership, applied epidemiology, Epidemic Intelligence Service, Centers for Disease Control and Prevention (U.S.)

Posted Date: January 11th, 2022

DOI: https://doi.org/10.21203/rs.3.rs-1247206/v1

License: (c) (i) This work is licensed under a Creative Commons Attribution 4.0 International License. Read Full License 


\section{Abstract \\ Background}

The U.S. Centers for Disease Control and Prevention (CDC) has administered the Epidemic Intelligence Service (EIS) fellowship for over 50 years, with the goal of developing scientists and leaders in applied epidemiology. Our objective was to understand the extent to which CDC EIS alumni are present in select public health leadership roles.

\section{Methods}

We conducted an evaluation describing EIS alumni representation in five preselected leadership positions (CDC director [1953-2016]; CDC center director, state epidemiologist, Field Epidemiology Training Program [FETP] resident advisor, and Career Epidemiology Field Officer [CEFO] [2000-2016]). We developed a dataset using multiple sources to identify staff in selected positions. We then matched these data with an internal EIS alumni dataset.

\section{Results}

Selected positions were staffed by 353 persons, of which 185 (52\%) were EIS alumni; 10 persons served in >1 leadership position, of which 6 were EIS alumni. Among 12 CDC directors, four (33\%) were EIS alumni; collectively these alumni led CDC for approximately 25 years. EIS alumni accounted for 29 (58\%) of 50 CDC center directors, 61 (35\%) of 175 state epidemiologists, 27 (56\%) of 48 Field Epidemiology Training Program resident advisors, and 70 (90\%) of 78 Career Epidemiology Field Officers. Of 185 EIS alumni in leadership positions, 136 (74\%) were physicians, 22 (12\%) were scientists, 21 (11\%) were veterinarians, 6 (3\%) were nurses; 94 (51\%) were assigned to a state or local health department. Among 61 EIS alumni who served as state epidemiologists, 40 (66\%) were assigned to a state or local health department during EIS.

\section{Conclusions}

EIS alumni accounted for between approximately one-third (CDC directors and state epidemiologists) and 90\% (CEFOs) of people serving in essential leadership positions at multiple levels.

\section{Introduction}

In 1951, the U.S. Centers for Disease Control and Prevention (CDC) inaugurated the first class of its foundational fellowship in field and applied epidemiology, known as the Epidemic Intelligence Service (EIS). One of the primary objectives of the EIS program has been to bolster the applied epidemiology workforce capacity of federal, state, and local government public health agencies domestically and internationally. ${ }^{1,2}$ The long-term goal of the fellowship is for EIS-trained epidemiologists to serve in leadership roles in public health settings. Initially, EIS focused on training physicians in the methods and strategies of field and applied epidemiology and disease surveillance. Over the years, EIS has been expanded to include doctoral-level scientists in public health-related disciplines (e.g., epidemiology, social and behavioral sciences), nurses, veterinarians, and some allied healthcare professionals. ${ }^{3}$

EIS is a two-year fellowship focused on developing applied epidemiological skills. The curriculum begins with a training course over approximately four weeks that introduces EIS officers to principles of applied epidemiology including public health surveillance, investigation of outbreaks, health communication, and emergency response. After EIS officers 
obtain this foundation, they report to their host sites at CDC or at a state, local, or territorial health department where they apply these concepts under the guidance of experienced supervisors, many of whom are EIS alumni. ${ }^{2}$ In their host sites, officers gain practical skills through hands-on learning experiences while simultaneously providing essential public health services and serving as frontline responders in public health emergencies. During the fellowship, each officer is required to participate in a field investigation, evaluate a public health surveillance system, analyze public health data, and present their work in the form of manuscripts, abstracts, reports, and presentations. ${ }^{4}$ The emphasis on practical experience gives EIS officers the opportunity to develop skills necessary to become epidemiologists who are equipped to address a spectrum of public health challenges. Among EIS graduates in recent classes, $>85 \%$ have worked in public health-related fields immediately after fellowship completion. ${ }^{2,5}$

Our evaluation of the EIS program is guided by an evaluation framework, which describes the association between program activities and intended outcomes. One long-term goal of the program is that EIS alumni serve in leadership roles in public health settings. Although a commentary by Thacker et al. in 2001 identified that $43 \%$ of state epidemiologists and three of 10 (30\%) CDC directors were EIS alumni, ${ }^{2}$ no systematic evaluations have been conducted to characterize the extent to which EIS alumni have served in these and other essential leadership positions. In this evaluation, we seek to provide evidence for a fundamental evaluation question: "Do EIS alumni serve as leaders within the public health workforce?" To answer this question, we examined the number of EIS alumni among persons who have served in selected public health workforce leadership roles at CDC and state or local health departments. Among EIS alumni that assumed the selected leadership positions, we also examined their characteristics and their EIS fellowship experience.

\section{Methods}

We focused the evaluation on five essential leadership positions at CDC or state or local health departments: CDC director, CDC center director, state epidemiologist, FETP resident advisor, and CEFOs. Though there are many other positions of leadership at CDC, we selected these five essential leadership positions based on the more readily available data sources. ${ }^{6}$ These selected positions represent varying degrees of leadership, and all these positions were also included because the structure and demands of the jobs require unique skills of critical thinking and evidencebased decision-making, particularly around surveillance, epidemiology, and statistics analysis, that EIS seeks to instill in its graduates to address public health needs at the national, state, local, territorial, tribal, and international levels.

CDC directors lead the largest public health organization in the United States, with the main objectives of improving national and global health security, reducing the largest causes of morbidity and mortality, and supporting and strengthening the collaboration between public health and healthcare systems. ${ }^{7} \mathrm{CDC}$ center directors organize and oversee the work of their respective centers within $\mathrm{CDC}{ }^{8}$ Although there are other important leadership positions at the division, branch, and team levels of CDC, the historical records are not easily traceable due to CDC's multiple reorganizations. State epidemiologists oversee state- or territory-wide programs for the surveillance, prevention, and control of diseases, coordinate epidemiologic investigations and surveys, and manage intervention services. ${ }^{9}$ State epidemiologists also coordinate disease surveillance and research activities of federal, state, and local officials in their jurisdictions, and communicate with media sources and public officials through conferences and policy briefs. FETP resident advisors are epidemiologists placed in countries around the world to provide technical and epidemiological assistance to ministries of health. Resident advisors are responsible for planning and organizing the implementation of FETPs in their host countries in a manner that best supports epidemiologic needs of the host country or region, as well as supervising and mentoring their trainees. ${ }^{10,11}$ CEFOs are federally funded CDC epidemiologists placed in state and 
major metropolitan health departments to strengthen their health departments' emergency preparedness and capacity for effective public health response. ${ }^{12}$

First, we constructed a dataset with the names of people who have held each of the five selected positions. For several reasons the evaluation focused on positions held from 2000-2016 for all positions except for the CDC Director. First the CEFO program was established in 2001 the attacks of September 11, 2001 so this time period included all the positions of interest. Second data was readily available through that period for all positions. Finally, for the position of CDC director we were able to obtain data dating back to 1953 , so this position was evaluated across a longer time period than the rest.

Using the History section of the online CDC webpage, "About CDC 24-7"

(https://www.cdc.gov/about/history/pastdirectors.htm), we found the tenure dates and names of all CDC directors and acting directors who served the agency during 1953-2016 (the first four directors who served during 1942-1953 were not included because they started their tenure before the first EIS class finished the fellowship). To compile names of $\mathrm{CDC}$ center directors, one investigator directly inquired with points of contact for each CDC center and the National Institute for Occupational Safety and Health and requested names and tenure dates of every director during 20002016. We also reviewed past CDC organizational charts, obtained using the Internet Archive (San Francisco, CA, https://archive.org/web/). For this evaluation, we defined CDC center directors as the people listed by name in CDC's organizational chart during their respective term of service, including directors of CDC coordinating centers, institutes and offices that were not horizontally related to the office of the director in the organizational chart. ${ }^{13}$ To compile $^{2}$ names of state epidemiologists who served during 2002-2016, we used information posted on the Council of State and Territorial Epidemiologists (CSTE) web site using the Internet Archive. The Internet Archive had copies of CSTE's web site dating back to 2002. To compile the list of state epidemiologists who served during 2000-2001, we used appendices of MMWR Surveillance Summaries (https://www.cdc.gov/mmwr/indss_2018.html), which listed state epidemiologists for those years. We obtained a list of names and tenure dates of Resident Advisors who served during 2000-2016 from an administrative database maintained by FETP at CDC's Center for Global Health. We acquired names and service dates of all CEFOs serving during 2001 (year in which the CEFO program began) through 2016 from CDC's Center for Preparedness and Response, which oversees CEFOs. For all types of positions, those designated as acting or interim were not included (i.e., people serving in the role temporarily in between terms of officially hired or appointed people).

We used an internal electronic dataset of all persons who participated in the EIS fellowship since 1951, stored in CDC's Fellowship Management System. Data elements included the first and last name of each officer, fellowship start year, host site assignment, and professional category (physician, nurse, scientist, nurse, or veterinarian). Professional categories were assessed in the following order which prioritized and individual's clinical degree (with the finalized assignment being the first category that characterized the officer): physician, veterinarian, nurse, or doctoral scientist. For example, a physician who also had a scientific doctoral-level degree would be considered a physician.

To match names of those identified as serving in the selected leadership positions with the names of EIS alumni, we first used a probabilistic matching program ${ }^{14}$ in SAS ${ }^{\circledR}$ version 9.1 (SAS Institute, Cary, NC). The program compared first and last names in EIS's alumni list with first and last names in lists of persons serving in each leadership position and calculated complex agreement patterns that allow for possible typographical errors. The edit distance proportion was used to develop match scores indicating the likelihood that the two records were a match. Records with match scores $>0$ were categorized as possible matches. Possible matches were reviewed manually. Finally, unmatched records in lists of persons serving in leadership positions were also reviewed by the authors and other EIS program staff to identify known matches that were not identified by the matching program due to last name changes or differences in

Page $4 / 11$ 
name conventions (e.g., Bill vs. William). We characterized EIS alumni who had served in selected leadership positions by professional category, type of EIS assignment (CDC vs state or local health department), and geographic location of the leadership position (for state epidemiologists, resident advisors, and CEFOs). In rare instances when the EIS officer changed assignment type during the fellowship, the assignment type at the end of the fellowship was used for purpose of this analysis. Several people in the sample served multiple times in the same type of leadership position (e.g., served as CEFO in multiple states); each person was counted only once for each type of leadership position. If an individual served in more than one type of leadership position they were counted for each category they served in. This project was reviewed by $\mathrm{CDC}$ and was deemed non-research, as it was considered a program evaluation that included only retrospective analysis of existing data.

\section{Results}

During the period of our evaluation, 353 people occupied the five leadership positions. We identified 12 people who had served as CDC directors during 1953-2016; during our evaluation period of 2000-2016, we identified 50 people who had served as center directors, 175 who had served as state epidemiologists, 48 who had served as FETP resident advisors, and 78 who had served as CEFOs. The people serving in these positions included 353 unique persons, of which 185 (52\%) were identified as EIS alumni. Of these 353 people, 10 had served in $>1$ type of leadership position during the time frames considered, of which six were EIS alumni.

Among 12 CDC directors during 1953-2016, four (33\%) were EIS alumni; collectively these alumni led the agency for approximately 25 years. During 2000-2016, 29 (58\%) of 50 CDC center directors were EIS alumni. State epidemiologists represented the largest group of leaders in our evaluation, 61 (35\%) of 175 were EIS alumni. Of the FETP resident advisors, 27 (56\%) of 48 were EIS alumni, and 70 (90\%) of 78 CEFOs were EIS alumni (Table).

Of the 184 EIS alumni serving in leadership positions, almost three-quarters (136 [74\%]) were physicians, 22 (12\%) were doctoral-level scientists, 21 (11\%) were veterinarians, and 6 (3\%) were nurses. Physicians were the most frequently represented professional category among EIS alumni who served in each leadership role examined. All CDC directors who were EIS alumni were physicians; $97 \%$ of EIS alumni who served as CDC center directors, $87 \%$ who served as state epidemiologists, 78\% who served as FETP resident advisors, and 51\% who served as CEFOs were physicians. Physicians were represented among all five leadership roles; doctoral scientists and veterinarians were represented among people serving in four and three of the roles assessed, respectively. Nurses were represented among State Epidemiologists and CEFOs (Table).

Ninety-three (51\%) of EIS alumni holding one of the leadership positions were placed in a field site (i.e., state or local health department), and 91 (49\%) were placed during their EIS fellowship at a center within CDC. Among four CDC directors who were EIS alumni, 2 (50\%) had their EIS assignment in CDC centers and $2(50 \%)$ in a field assignment (50\%). CDC center directors were more often placed at a CDC center (76\%) during their EIS fellowship, as were FETP resident advisors (70\%). Conversely, state epidemiologists and CEFOs had more representation from EIS alumni who had field assignments (66\% and $59 \%$ of EIS alumni in these positions, respectively).

EIS graduates have served as State Epidemiologists and CEFOs throughout the United States, territories, and the District of Columbia during 2000-2016. During this period, 35 states, Puerto Rico, and the U.S. Virgin Islands had a state or territorial epidemiologist who was an EIS alumnus. Thirty-two states, Washington, D.C., Puerto Rico, and the U.S.affiliated Pacific Islands[1] had a CEFO who was an EIS alumnus. Twenty-two states and Puerto Rico both had at least one state epidemiologist and at least one CEFO who were EIS alumni during the evaluation period (Figure 1). All but five states have had either a state or territorial epidemiologist or a CEFO who was an EIS alumnus during the evaluation period. FETP resident advisors have served in a total of 29 countries and three regional positions comprising more than 
one country during the evaluation period. FETP resident advisors who were EIS alumni have served in 19 countries (66\% of countries that have resident advisors) and one regional position (Figure 2).

[1] The U.S.-affiliated Pacific Islands include the following: American Samoa, the Commonwealth of the Northern Mariana Islands, Guam, the Republic of Palau, the Federated States of Micronesia, and the Republic of the Marshall Islands.

\section{Discussion}

Our evaluation demonstrated that alumni of CDC's EIS fellowship are represented among five select leadership positions at multiple levels of the workforce. We found that EIS alumni accounted for between approximately one-third (CDC directors and state epidemiologists) and the majority (up to $90 \%$ for CEFOs) of select public health leadership positions across CDC and state and local health departments. Although we only examined a select set of positions, this initial descriptive evaluation suggests that EIS consistently serves as a pipeline for public health leaders at the national, state, and territorial levels, consistent with other evaluations. ${ }^{1-3}$

Not surprisingly, we found that the majority of EIS graduates serving as state epidemiologists had a field assignment at a state or local health department during their fellowship. An analysis of EIS officers serving during 1991-1996 found that officers placed in host sites at state or local health departments were more likely to select a state or local health department as their first post fellowship position, compared with persons placed at a CDC center. ${ }^{15}$ This finding reinforces the importance of having EIS officers assigned to state or local health departments to promote a pipeline of field-based public health leaders trained in applied epidemiology.

We also found that physicians were well represented among EIS alumni who served in these leadership positions. Many of the alumni in this evaluation's leadership positions were from earlier EIS classes, and this might explain the higher percentage of physicians in leadership positions we observed. ${ }^{16}$ In addition, physicians have historically been preferentially selected for public health leadership positions overall. Despite this trend, more recent EIS classes have had higher representation of nonphysician professional categories (the 2020 EIS class includes $45 \%$ doctoral scientists, $35 \%$ physicians, $10 \%$ veterinarians, $8 \%$ nurses, and a physical therapist). ${ }^{4}$ If EIS is a pipeline to leadership irrespective of professional category, we would expect an increasing number of EIS trained non-physicians to assume these leadership positions in the future.

Our evaluation has limitations. We did not have longitudinal information about the career trajectories of EIS alumni, so we could not examine percentage of EIS alumni who have served in any leadership positions. Additionally, we focused solely on applied epidemiology leadership positions for which we had access to reliable data. Therefore, our evaluation does not allow us to answer the question of the extent to which EIS is a pipeline to any leadership position. Our approach effectively excluded other roles that could conceived as leadership positions (e.g., health department commissioners), positions in academia (e.g., faculty positions in schools of public health), or other positions crucial for epidemiologic field investigations or emergency response. ${ }^{17}$ Finally, it should be noted that the selected types of positions differ greatly in the degree to which they represent senior leadership positions. CDC directors and CDC center directors represent relatively more senior positions while CEFOs and FETP resident advisors represent less senior positions. Collectively, our approach leveraged existing data sources to optimize the feasibility of this evaluation and yield timely, actionable insights to guide program improvement. This evaluation is a preliminary step in providing data on the extent to which EIS is a pipeline to leadership positions at CDC and at state and local health departments.

Ideally, EIS training would prepare officers for critical leadership roles within the public health workforce. Previous studies have shown that cross-cutting skills that transcend epidemiologic statistical methods and include collaborative 
engagement, change management, persuasive communication, and systems thinking are among the most important knowledge, skills, and attitudes for the contemporary public health workforce. ${ }^{18-20}$ Collectively, this literature suggests that intractable public health problems require epidemiologists to possess skillsets beyond research and analytic responsibilities. Ongoing efforts to inculcate these competencies into EIS training, and evaluate the impact of such activities, remain important. Incorporation of mixed-methods approaches could shed additional light on how EIS graduates have contributed to science and practice.

Additional efforts are underway to advance capacities of EIS graduates including a focus on communication science, data science, and racism as a public health issue. CDC's Preventive Medicine Residency and Fellowship focuses on enhancing skills in program evaluation, management, policy, and population health improvement for EIS graduates. ${ }^{21}$ In addition, CDC started the Future Leaders in Infections and Global Health Threats (FLIGHT) program in 2019 to foster leadership development among graduating EIS officers with medical or veterinary degrees. The program is designed to equip participants with scientific leadership skills and the capability to translate public health research into effective global infectious disease programs. As the evidence on FLIGHT becomes available, this leadership program could be expanded to other non-clinical professionals. Tracking the process and outcome indicators of training initiatives are important for identifying specific workforce development strategies to disseminate at scale.

\section{Abbreviations}

CDC

Centers for Disease Control and Prevention (U.S.)

CEFO

Career Epidemiology Field Officer

EIS

Epidemic Intelligence Service

FETP

Field Epidemiology Training Program

FLIGHT

Future Leaders in Infections and Global Health Threats

\section{Declarations}

Ethics approval and consent to participate. This project was reviewed by CDC and was deemed non-research, as it was considered a program evaluation that included only retrospective analysis of existing data.

Consent for publication. Not applicable.

Availability of data and materials. The dataset analyzed during the current study are not publicly available as they represent internal records of the $\mathrm{CDC}$, but may be available from the corresponding author on reasonable request.

Competing interests. The authors have no financial relationships to disclose. The authors declare that they have no conflicts of interest.

Funding. This publication was supported in part by an appointment to the Research Participation Program at the CDC by the Oak Ridge Institute for Science and Education through an interagency agreement between the U.S. Department of Energy and CDC.

Authors' contributions.

Page $7 / 11$ 
MS wrote the initial draft of the manuscript, carried out elements of the analysis, generated figures and tables, and interpreted results and their implications. AW conceptualized the study, was instrumental in acquisition and cleaning of the data, carried out elements of the analysis, interpreted results and their implications, and reviewed the manuscript for important intellectual content. SF was instrumental in acquisition and cleaning of the data, interpreted results and their implications, and reviewed the manuscript for important intellectual content. DE, DC, PS, EP interpreted results and their implications, and reviewed and revised the manuscript for important intellectual content. WA conceptualized the study, supervised the study, and reviewed the manuscript for important intellectual content. All authors approved the final manuscript as submitted and agree to be accountable for all aspects of the work.

Acknowledgments. We are grateful to Sarah Gojer for her assistance gathering data concerning state epidemiologists. We are also grateful to Byron Robinson, Chad Heilig, and Stephanie Dietz for their statistical support and name matching algorithms. The findings and conclusions in this report are those of the authors and do not necessarily represent the official position of the CDC.

\section{References}

1. Koplan JP, Thacker SB. Fifty Years of Epidemiology at the Centers for Disease Control and Prevention: Significant and Consequential. Am J Epidemiol. 2001;154(11):982-4. doi:10.1093/aje/154.11.982.

2. Thacker SB, Dannenberg AL, Hamilton DH. Epidemic Intelligence Service of the Centers for Disease Control and Prevention: 50 Years of Training and Service in Applied Epidemiology. Am J Epidemiol. 2001;154(11):985-92. doi:10.1093/aje/154.11.985.

3. Buffington J, Lyerla RL, Thacker SB. Nonmedical doctoral-level scientists in the Centers for Disease Control and Prevention's Epidemic Intelligence Service, 1964-1997. Am J Prev Med. 1999;16(4):341-6. doi:10.1016/S07493797(99)00027-6.

4. Epidemic IS. 2018 Annual Update; 2018. https://www.cdc.gov/eis/downloads/eis-annual-update-2018-508.pdf.

5. Centers for Disease Control and Prevention. Epidemic Intelligence Service (EIS) 2020 Annual Update.; 2020.

Accessed March 10, 2021. https://www.cdc.gov/eis/downloads/eis-annual-update-2020-508.pdf.

6. Centers for Disease Control and Prevention. Framework for program evaluation in public health. MMWR Morb Mortal Wkly Rep. 1999;48(RR-11):1-40.

7. CDC Strategic Framework: Centers for Disease Control and Prevention's Strategic Framework FY 2016-FY 2020. Published 2016. Accessed May 25. 2018. https://www.cdc.gov/about/organization/strategicframework/index.html.

8. Official Mission Statements \& Organizational Charts. Centers for Disease Control and Prevention. Published 2017. Accessed December 27. 2017. https://www.cdc.gov/maso/officialmissionstatementscharts.html.

9. The New State Epidemiologist's First Days: A Planning Guide. Accessed December 27, 2017. http://c.ymcdn.com/sites/www.cste.org/resource/resmgr/StateEPIHomepage/The_New_State_Epidemiologist.pdf.

10. Field Epidemiology Training Program Development Handbook.; 2006. Accessed December 27, 2017. https://www.cdc.gov/globalhealth/healthprotection/fetp/pdf/fetp_development_handbook_508.pdf.

11. Subramanian RE, Herrera DG, Kelly PM. An evaluation of the global network of field epidemiology and laboratory training programmes: a resource for improving public health capacity and increasing the number of public health professionals worldwide. Hum Resour Health. 2013;11:45. doi:10.1186/1478-4491-11-45.

12. Inglesby T, Ellis B. Career Epidemiology Field Officer (CEFO) Program Review.; 2012. Accessed December 27, 2017. https://www.cdc.gov/phpr/science/documents/cefo_program_review_workgroup_report_final2.pdf. 
13. CDC Organizational Chart. Accessed May 12. 2019. https://www.cdc.gov/about/pdf/organization/cdc-orgchart.pdf.

14. Sayers A, Ben-Shlomo Y, Blom AW, Steele F. Probabilistic record linkage. Int J Epidemiol. 2016;45(3):954-64. doi:10.1093/ije/dyv322.

15. Moolenaar RL, Thacker SB. Evaluation of field training in the epidemic intelligence service: publications and job choices. Am J Prev Med. 2004;26(4):299-306. doi:10.1016/j.amepre.2003.12.014.

16. Thacker SB, Goodman RA, Dicker RC. Training and service in public health practice, 1951-90 - CDC's epidemic intelligence service. Public Health Rep. 1990;105(6):599-604.

17. Davis JP, Birkhead GS. Field Investigations From the State and Local Health Department Perspective. Field Epidemiology. Oxford University Press; 2008:pp. 397-418. doi:10.1093/acprof:oso/9780195313802.003.0020.

18. Chapple-McGruder T, Leider JP, Beck AJ, et al. Examining state health agency epidemiologists and their training needs. Ann Epidemiol. 2017;27(2):83-8. doi:10.1016/j.annepidem.2016.11.007.

19. Kaufman NJ, Castrucci BC, Pearsol J, et al. Thinking beyond the silos: emerging priorities in workforce development for state and local government public health agencies. J Public Health Manag Pract. 2014;20(6):557-65. doi:10.1097/PHH.0000000000000076.

20. Brownson RC, Samet JM, Chavez GF, et al. Charting a future for epidemiologic training. Ann Epidemiol. 2015;25(6):458-65. doi:10.1016/j.annepidem.2015.03.002.

21. Preventive Medicine Residency and Fellowship (PMR/F). Centers for Disease Control and Prevention.

\section{Tables}

Table. Characteristics of Epidemic Intelligence Service (EIS) Alumni in Selected Public Health Leadership Positions 


\begin{tabular}{|c|c|c|c|c|c|c|}
\hline ;teristic & $\begin{array}{c}\text { CDC } \\
\text { Director }\end{array}$ & $\begin{array}{c}\text { CDC } \\
\text { Center } \\
\text { Director }\end{array}$ & $\begin{array}{c}\text { State } \\
\text { Epidemiologist }\end{array}$ & $\begin{array}{l}\text { FETP } \\
\text { Resident } \\
\text { Advisor }\end{array}$ & $\begin{array}{c}\text { Career } \\
\text { Epidemiology } \\
\text { Field Officer }\end{array}$ & $\begin{array}{c}\text { Total, } \\
\text { excluding } \\
\text { duplicates } \\
\end{array}$ \\
\hline ncluded & $\begin{array}{l}1953- \\
2016\end{array}$ & $\begin{array}{l}2000- \\
2016\end{array}$ & $2000-2016$ & $\begin{array}{l}2000- \\
2016\end{array}$ & $2001-2016$ & N/A \\
\hline $\begin{array}{l}\text { umber of } \\
\text { serving in } \\
\text { n during the } \\
\text { d years }\end{array}$ & 12 & 50 & 175 & 48 & 78 & 353 \\
\hline $\begin{array}{l}\text { r of EIS alumni } \\
\text { in position, }\end{array}$ & $4(33)$ & $29(58)$ & 61 (35) & 27 (56) & $70(90)$ & $185(52)$ \\
\hline ession, N (\%) & & & & & & \\
\hline 'hysician & $4(100)$ & $28(97)$ & $52(85)$ & $21(78)$ & $36(51)$ & $136(74)$ \\
\hline $\begin{array}{l}\text { octoral } \\
\text { cientist }\end{array}$ & $0(0)$ & $1(3)$ & $4(7)$ & $4(15)$ & $14(20)$ & $22(12)$ \\
\hline $\bar{l}$ eterinarian & $0(0)$ & $0(0)$ & $4(7)$ & $2(7)$ & $15(21)$ & $21(11)$ \\
\hline Jurse & $0(0)$ & $0(0)$ & $1(2)$ & $0(0)$ & $5(7)$ & $6(3)$ \\
\hline $\begin{array}{l}\text { Assignment } \\
\text { t, N (\%) }\end{array}$ & & & & & & \\
\hline $\begin{array}{l}\text { DC Center or } \\
\text { Ieadquarters }\end{array}$ & $2(50)$ & $22(76)$ & $21(34)$ & $19(70)$ & $29(41)$ & 91 (49) \\
\hline $\begin{array}{l}\text { tate, } \\
\text { erritorial, or } \\
\text { ccal health } \\
\text { epartment }\end{array}$ & $2(50)$ & $7(24)$ & $40(66)$ & $8(30)$ & 41 (59) & $94(51)$ \\
\hline
\end{tabular}

iations: CDC, Centers for Disease Control and Prevention; FETP, Field Epidemiology Training $\mathrm{m}$

\section{Figures}

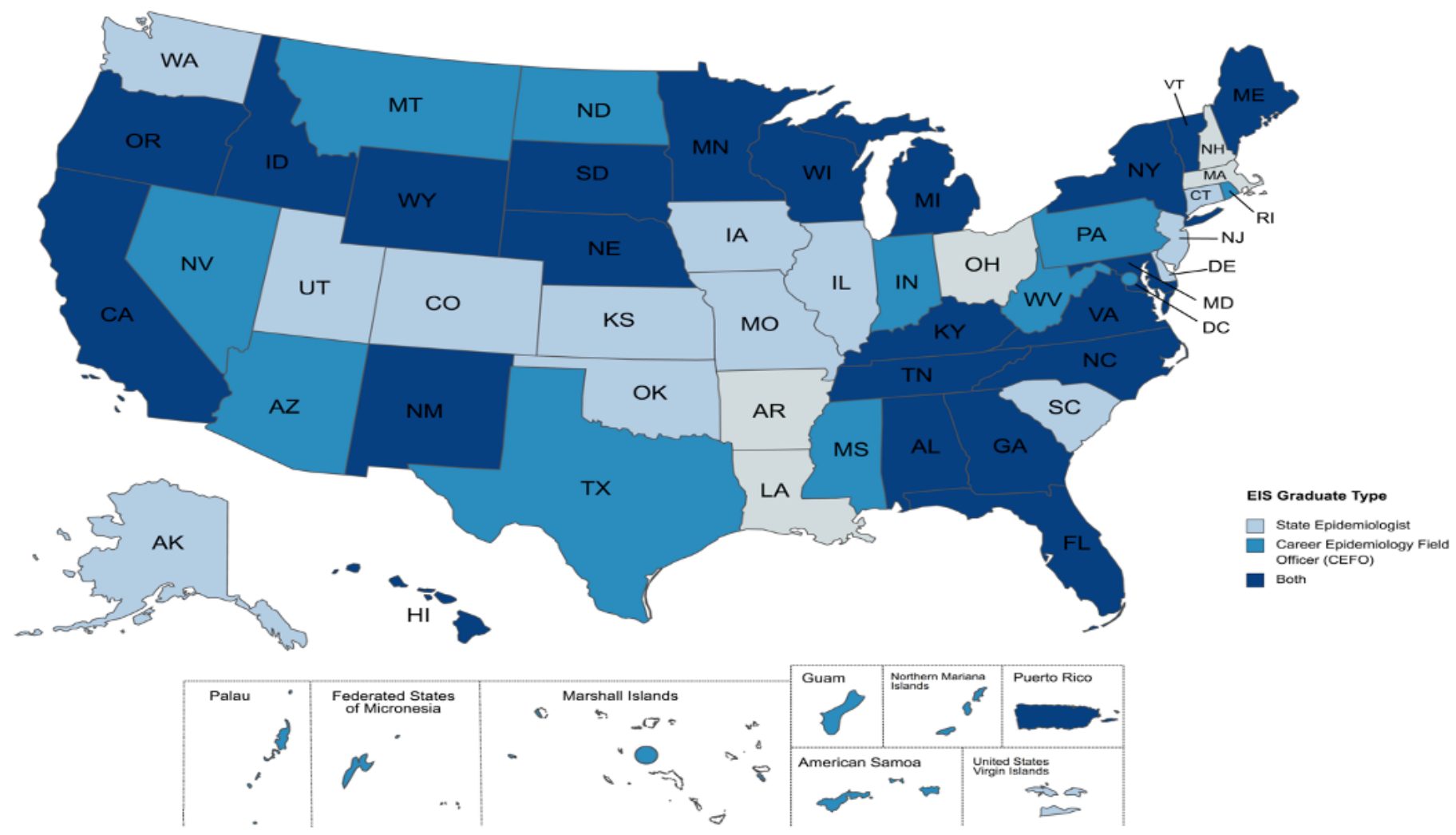

Figure 1 
States in which an Epidemic Intelligence Service (EIS) Alumnus Has Served as the State Epidemiologist, Career Epidemiology Field Officer, or Both Positions, 2000-2016

Note. CEFOs assigned to New York were all assigned to the New York City Department of Health and Mental Hygiene. All six U.S.-affiliated Pacific Islands are served by one CEFO.

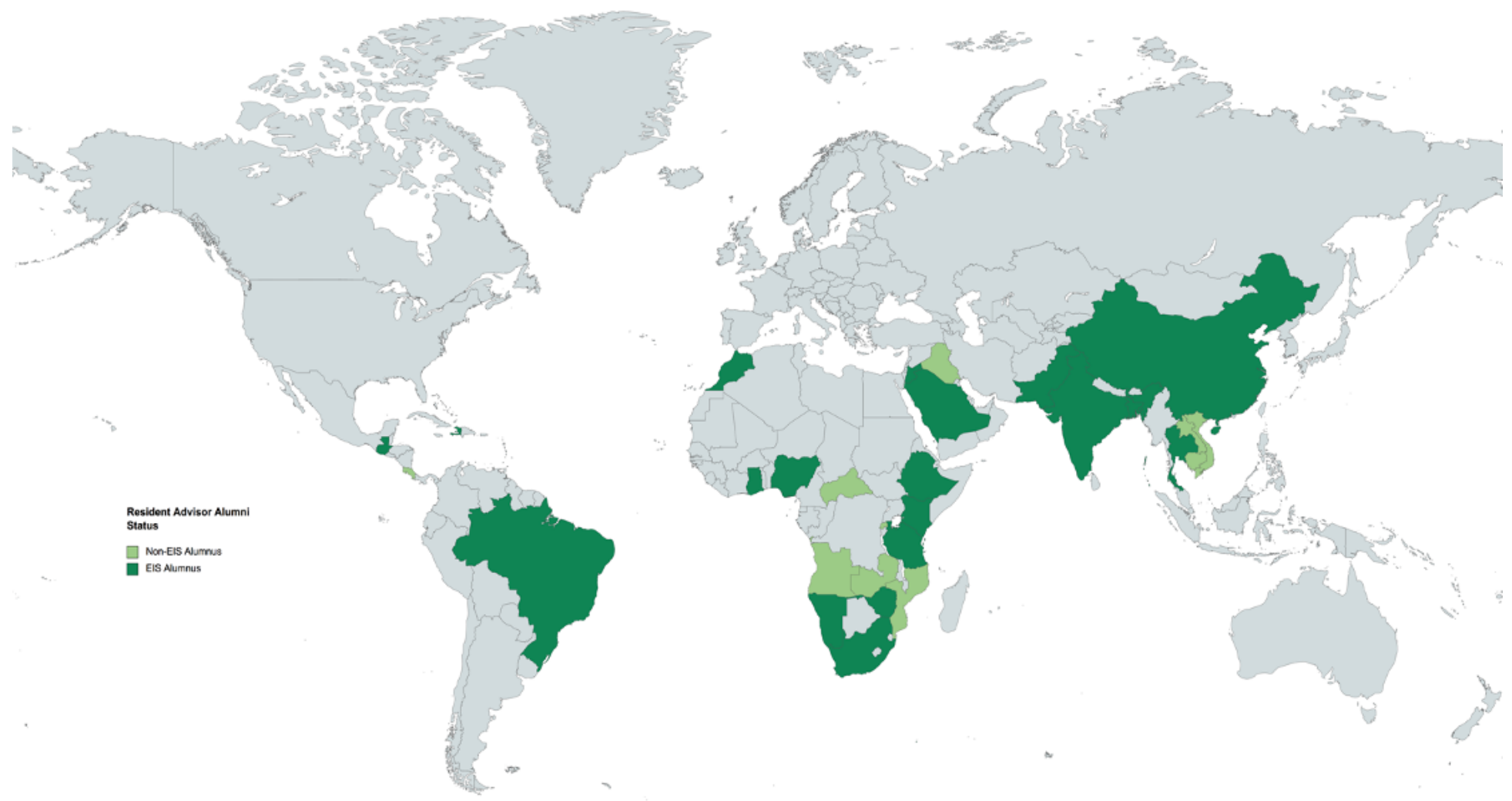

Figure 2

Countries with Field Epidemiology Training Program Resident Advisors, by Epidemic Intelligence Service (EIS) Alumni Status, 2000-2016

Note. Three Career Epidemiology Field Officers were assigned at the regional level and not reflected on this map. 